\title{
MicroGeneSys drops out of NIH trial for AIDS vaccine
}

Washington. The AIDS vaccine that the US Army intends to use exclusively in a $\$ 20$ million trial programme has been withdrawn by its maker from the main comparative trials being organized by US public health agencies in a move that deepens already bitter divisions within the AIDS research community.

\section{UNAVAILABLE} FOR COPYRIGHT REASONS
The gp 160 vaccine, known commercially as VaxSyn, consists of the outer envelope protein of the AIDS virus and is intended to boost the immune systems of people already infected with HIV.

Although NIH has declined to wage a public war of words against MicroGeneSys, officials are privately furious at the company's withdrawal and do not accept its explanation. "This was the only study giving direct comparability between rival vaccines", says one. "But put yourself in their shoes: why would they want to help generate data showing that their vaccine offers less immunogenicity than others?"

The president of MicroGeneSys, Franklin Volvovitz, says that the suggestion that his company fears the results of the proposed trials is "preposterous". "It's bizarre for them to say these things", says Volvovitz about NIH. "We disagreed with the primary and secondary end-points set for protocol 214 . As the firm with the largest database, our views should be considered."

Volvovitz says that MicroGeneSys has been repeatedly excluded from another $\mathrm{NIH}$ competitive study, protocol 209, that monitors the effect of vaccines on patients' response to the AIDS drug AZT. Last

\section{Clinton accepts court's ruling on Antarctica}

Washington. The US government has abandoned its longstanding opposition to applying a 23-year-old environmental law to activities in Antarctica, a reversal that the National Science Foundation (NSF) says will require it to spend hundreds of thousands of dollars a year on unproductive administration instead of on science.

Last week, President Bill Clinton rejected a plea by several federal agencies to contest a recent ruling by the US Court of Appeals involving the construction of an incinerator at a US base at McMurdo Station (see Nature 361, 482; 1993). The court had ruled on 29 January that NSF must follow the requirements of the National Environmental Protection Act (NEPA). A lower court will now decide whether NSF has acted properly in building the incinerator.

The government has long claimed an exemption from NEPA for reasons of national security and for matters of state covering such activities as overseas military bases and economic development projects in the developing world. In deciding not to file an appeal, Clinton struck a compromise by accepting NEPA's jurisdiction over Antarctica while insisting that "the adminis-

tration does not embrace language in the opinion that may be interpreted to extend beyond this holding".

The Environmental Defense Fund, which brought the suit in 1991, says that there is no reason for NSF to be exempt from a law that it must follow in the United States. But NSF officials see the decision as a 'litmus test' that allows the president to flaunt his environmental convictions at the expense of a science agency that insists it already follows procedures at least as strict as those under NEPA. To emphasize that point, the $\mathrm{Na}$ tional Science Board, NSF's governing body, last week passed a resolution affirming its support for a 1991 agreement intended to protect the Antarctic continent.

NSF estimates that it will have to employ three or four people to conduct and write up the environmental impact statements required by NEPA. The act also makes NSF vulnerable to what its director, Walter Massey, called "frivolous suits" by environmental groups that could impede research. "We do not feel that we will have to change the way we operate in Antarctica", he adds, "but the extensive documentation will cost a lot of money for a little agency like NSF." Jeffrey Mervis summer, the team running the protocol told the company that its limited resources would be best used to study a single vaccine developed by Genentech.

MicroGeneSys's successful effort last autumn to persuade Congress to give the US Army $\$ 20$ million for large-scale trials of its gp160 vaccine has aroused anger and jealousy within the AIDS research community (see Nature 360, 94; 1992). Critics of the special appropriation, which drew energetic support from AIDS activists, believed that clinical trials were premature.

That assessment was endorsed in November by a panel of experts convened by the NIH director, Bernadine Healy, but the panel nonetheless agreed that the Army programme should proceed "on compassionate grounds" as long as more than one vaccine is used. But the Army, which must notify Congress by 6 April of its plans, is now expected to propose stipulations for inclusion in its clinical trials that only the MicroGeneSys vaccine can meet.

In a further development, Colonel Robert Redfield, an Army scientist closely involved in the design of the test programme, is said to have been cleared by an internal Army investigation into allegations that he had overstated the effectiveness of the gp 160 vaccine at a public meeting in Amsterdam last July. Redfield declined to comment, saying that "I'm trying to stay out of the gossip pages and do my science".

$\mathrm{NIH}$ is now likely to proceed with a protocol 214 based on comparative trials between gp120 vaccines produced by two California companies, Genentech and Chiron.

Colin Macilwain

\section{Geneticists win Crafoord Prize}

Two scientists who have developed radically different approaches to the genetic basis of behaviour in animals have been jointly awarded this year's Crafoord Prize by the Royal Swedish Academy of Sciences. The SKr2.6 million (US $\$ 300,000$ ) prize is to be shared by Seymour Benzer of the California Institute of Technology and Richard Hamilton of the University of Oxford. Benzer is best known for his studies of the genetic and neurophysiological basis of behavioural mutants in the fruit fly Drosophila melanogaster, and Hamilton for his theoretical work on the way in which kin selection and genetic relationships act as prerequisites for the evolution of altruistic behaviour.

David Dickson 